\title{
O Crepúsculo da Realidade e a Ironia Melancólica do Sucesso Brilhante e Duradouro: reflexões sobre os Interpretantes Emocionais e Lógicos nos Modos peircianos de Fixação das Crenças
}

The Twilight of Reality and the Melancholic Irony of Brilliant, Unlasting Success: Reflecting on Emotional and Logical Interpretants in Peirce's Modes for Fixation of Beliefs

\begin{abstract}
Resumo: A Fixação da Crença (1877) é, provavelmente, um dos mais famosos ensaios entre todos publicados por Charles S. Peirce (1839-1914) em sua vida. Neste ensaio, Peirce propôs quatro métodos segundo os quais as crenças humanas podem se tornar fixas, a saber, tenacidade, autoridade, a priori e científica. Todavia, considero que a riqueza e originalidade deste ensaio ainda não foram suficientemente exploradas, principalmente quando fazemos uso dos conceitos e vocabulário da Semiótica para uma análise mais profunda das consequências pragmáticas desses métodos de fixação. Assim, algumas das questões seguintes podem ser formuladas: quais modos de cognição ou, em outras palavras, quais interpretantes lógicos estão ligados a essas crenças? Que tipo de conjecturas sobre os interpretantes emocionais pode ser proposto, levando em conta sua possível consideração pela psicanálise? Que tipo de ação cada uma suscita, a partir de seu lado externo que permite inferir a natureza geral da respectiva crença com seu lado interno? Essas questões, supostamente, abririam um novo e interessante nível especulativo para entender os quatro tipos de crença e, consequentemente, dos hábitos associados a cada um deles. Para lidar com essas questões, pretendo utilizar o conceito de dialogia semiótica como um processo que oferece continuidade para formas lógicas gerais capazes de comunicação e crescimento. Será ressaltado que, quando essa continuidade for bloqueada ou truncada, as crenças dogmáticas, então, surgirão.
\end{abstract}

Palavras-chave: Peirce, crenças pragmáticas, interpretantes, dialogia semiótica

\begin{abstract}
The Fixation of Belief (1877) probably is one of the most famous among the papers published by Charles S. Peirce (1839-1914) during his lifetime. In this essay, Peirce proposed four methods hereby human beliefs may become fixed, namely, tenacity, authority, a priori and scientific. However, I consider that the richness and originality of this paper were not yet completely explored, mainly when we make use of the concepts and vocabulary of Semiotics for a deeper analysis of the pragmatic consequences of such fixation methods. Then, some of the following questions can be formulated: which cognition modes or, in other words, which logical interpretants are connected with these beliefs? What sort of conjectures about the emotional interpretants could be proposed, taking into account their possible consideration by psychoanalysis? To what types of action each one gives rise, as their external side that allows inferring the general nature of the respective belief as its internal side? These questions, supposedly, would open an interesting new speculative level for understanding the four types of belief and, consequently, of the habits that are associated with each one. To treat such questions, I intend to use the concept of semiotic dialogy as a process that provides continuity towards general logical forms capable of communication and growth. It will be highlighted that, when this continuity becomes blocked or truncated, dogmatic beliefs consequently arise.
\end{abstract}

Keywords: Peirce, pragmatic beliefs, interpretants. semiotic dialogy. 


\section{Considerações gerais sobre a natureza dos interpretantes}

Os estudiosos de Peirce certamente conhecem seu famoso texto The Fixation of Belief ${ }^{2}$, um dos raros publicados entre a vasta obra do autor. Nele, Peirce elenca quatro tipos de crenças que parecem pretender esgotar os modos pelos quais elas são humanamente fixadas e, por assim serem, pragmaticamente moldam o modo como um indivíduo, ou mesmo uma inteira comunidade, estão dispostos ou propensos a agir. Peirce, no ensaio, faz uma espécie de inventário das condições pelas quais um ou outro modo se fixa, e vale, aqui, explicitar o sentido do uso do termo 'fixação'. Creio que ele se justifica ao se recorrer à conceituação do que seja uma crença segundo Peirce, a saber, que ela é concebida como um hábito de ação ${ }^{3}$, um modo de agir segundo o qual se evidencia redundância de conduta. Parece razoável pensar a ideia de hábito como regra de ação que se fixa na mente do agente, seja ele individual ou coletivo, uma vez que é de sua própria essência promover ações redundantes, ou seja, condutas similares sob condições similares. Já aqui, tomando essa conceituação como clara, as seguintes questões parecem ser apropriadas:

[a] Por que a mente humana ${ }^{4}$ necessita de crenças?

[b] A resposta à essa questão [a] seria também capaz de justificar por que o homem desenvolve hábitos?

Há na obra de Peirce passagens bem conhecidas que confrontam os estados mentais de crença com aqueles de dúvida, afirmando, por um lado, o desconforto psicológico gerado pela dúvida e, contrariamente, a relativa serena rotina, poder-se-ia assim dizer, proporcionado pelo estado de crença. Evidentemente esses estados associam-se ao que Peirce denomina crenças e dúvidas reais, a saber, aquelas que têm consequências para a conduta - são elas as que têm, em outras palavras, sentido pragmático. Sabe-se, também, como Peirce recusa todos os tipos de ceticismo que nascem e permanecem apenas no plano teórico, especulativo, sem

\footnotetext{
${ }^{2}$ EP 1. 109-123.

${ }^{3}$ Ver W 3.247 / EP 1. 114. "O sentimento de acreditar é mais ou menos uma indicação certa de que se estabeleceu em nossa natureza algum hábito que determinará as nossas ações.”

${ }^{4}$ Confinarei por ora a ideia de mente ao universo humano, não obstante se saiba da amplitude que ela assume na filosofia de Peirce mediante o que propõe seu Idealismo Objetivo.
} 
acarretarem consequências práticas, ou seja, sem possivelmente afetarem a conduta. À luz de seu pragmatismo, tais correntes céticas são destituídas de significado. É interessante ressaltar como a condição de significação já na filosofia jovem de Peirce se estabelece como uma espécie de aparecer do conceito na forma da ação. Não por outra razão, faculta-se o acesso às crenças de outras mentes pelo modo como elas se manifestam publicamente, entendendo público todo conjunto de objetos que podem proporcionar uma comunitária experiência direta. Em outros termos, o conceito de ação se torna ontologicamente significativo, por denotar como se dá a relação entre mundo interno, configurado por crenças, hábitos, conceitos, com o mundo externo, público, ao qual qualquer mente tem potencial e circunstancialmente acesso direto. Ao afirmar que "todo conhecimento do mundo interno é derivado, por raciocínio hipotético, do nosso conhecimento de fatos externos"5, Peirce confirma o que já se anunciava em sua juventude pela exigência de significado pragmático que, segundo ele, não era cumprido pela maioria dos 'falsos ceticismos'

À questão [a] retro formulada de certa forma Peirce responde contrastando os estados psicológicos da mente que duvida e da que crê, como já se havia acentuado. Em seu estágio maduro de reflexão, ele faz uma autocrítica de seu trabalho, acusando-se de nominalista. Em verdade, parece-me que o mais correto seria reconhecer que o realismo sempre foi embrionário, genético, em sua obra e que o seu desenvolvimento teórico gradativamente passa a exigir não apenas mudança de vocabulário, mas sua amplificação em função do surgimento de novas doutrinas filosóficas, notadamente as de cunho metafísico. Esse movimento acarretou o total abandono de termos de natureza psicológica, concomitantemente com sua insistência na necessidade de se discernir entre psicologia e lógica. De fato, melhor que afirmar um possivelmente universal 'desconforto' criado pelo estado de dúvida, seria justificar a necessidade de se estabelecerem crenças por um viés fenomenológico e semiótico. Essa tarefa é também de natureza pragmática, pois crenças genuínas são guias de conduta. E por que não afirmar, em sentido ontologicamente forte, que adotar uma conduta é, em linhas gerais, decidir existir, participar de um teatro de reações - termo peirciano - em conjunto com outros seres existentes. Adotar uma conduta implica em algum exercício de racionalidade que

\footnotetext{
5 "Algumas consequências de quatro incapacidades" (CP 5.264-317).
} 
construa mediações em relação a um mundo reativo, habitado fundamentalmente pela alteridade cuja natureza não se submete às representações que dela possamos fazer, sejam por conceitos, sejam por projeções da vontade. Estamos, agora, não somente no ambiente fenomenológico- semiótico da filosofia de Peirce como, também, inseridos no esquema de suas categorias. Precisamos construir mediações que representem a alteridade e permanentemente interpretar suas ações. Fenomenologicamente, precisamos saber o que poderá vir acontecer no tempo futuro, para ajustarmos nossa conduta aos fatos. Aqui já, pareceme claro, se justificam as crenças - elas são hábitos de ação que se associam a uma conduta redundante por que atingem os fins que se desejam - e aqui, parece-me que a questão [b] é de alguma maneira considerada. Ao se afirmar isso, contudo, surge a questão mais complexa que, se pode supor, estaria intimamente ligada à proposta desse ensaio. Que fins seriam esses e como eles se vinculariam à natureza de dois dos mais importantes interpretantes da Semiótica de Peirce - o lógico e o emocional. Realço aqui dois deles, por supor que os demais tipos de interpretantes são, de certa forma, a eles intimamente associados, a saber: o imediato, o dinâmico, o energético, e o final. Em linhas gerais, sob o ponto de vista do pragmatismo, os interpretantes devem se mostrar potencialmente acessíveis à cognição de outras mentes, o que, de certa forma, acabam por envolver os interpretantes energético e final na medida em que a ação deles decorrente evidenciar-se inteligente, ou seja, teleológica. Os assim denominados imediato e dinâmico envolvem relações específicas com o tempo, como o fazem o emocional e o lógico, na forma de imediação e mediação. Importa, nesse ensaio, distinguir interpretantes que ensejam ações decorrentes de continuidade puramente qualitativa, como o são as emoções, o universo dos sentimentos - o contínuo dos qualisignos, para ser mais fiel ao vocabulário semiótico - dos interpretantes associadas a ações decorrentes de continuidade lógica, ou seja, constituída por relações gerais entre variáveis espaço-temporais. À margem da complexidade que envolve essa classificação, uma síntese possível dos interpretantes estaria baseada no poder preditivo de cada um deles. Assim, interpretantes emocionais e imediatos são signos descomprometidos com o Cronos $^{6}$. O energético insere o interpretante em

\footnotetext{
${ }^{6}$ Uso esse termo no sentido de tempo objetivo, sob a terceira categoria.
} 
sua dimensão existencial, como sinsigno, propiciando alguma forma de ação. Os interpretantes dinâmico, final e lógico são aqueles que, de acordo com suas respectivas naturezas, se inserem na temporalidade. $\mathrm{O}$ interpretante dinâmico deve ser fenomenologicamente dialogante para que se preste a suporte da formação de interpretantes lógicos que se orientem de modo supostamente verdadeiro para interpretantes finais.

Com essas considerações, malgrado se deva reconhecê-las sucintas em função das limitações de espaço desse ensaio, busco justificar, em linhas gerais, meu foco nos interpretantes emocionais e lógicos, interessando aqui seus caracteres imediato e mediato, respectivamente. Isso os faz diferentemente comprometidos com o tempo Cronos, pela sua subjetivação mais ou menos aguda sob o tempo Kairos ${ }^{7}$. Os interpretantes lógicos levam pragmaticamente a condutas dirigidas sob hipóteses de conduta da alteridade no futuro, ou sob hábitos bem-sucedidos porque conducentes a fins desejados. Os interpretantes emocionais pragmaticamente levam a ações que não tomam em conta o futuro e, assim, são tipicamente ações marcadas pela sua presentidade. Os contínuos de qualidades que caracterizam os interpretantes emocionais não contêm regras projetivas direcionadas à conduta futura dos fatos, da alteridade. Não à toa tais contínuos são logicamente associados a possibilidades e não contêm forma lógica. Seu lado exterior aparece apenas como existência, como segundidade, sem ser uma réplica ou um sinsigno capaz de inserir-se como instância de um legisigno. Supõe-se que, ao contrário, o interpretante lógico, pragmaticamente, faz incorrer ações que se inserem em uma regra definidora de conduta, dotada, portanto, de alguma forma lógica. Eles pretendem ter poder preditivo e, assim, seriam deliberativos para a conduta futura que se torna mediada por eles.

É tempo, suponho, de refletirmos mais detidamente sobre as formas de fixação de crenças tais como propostas por Peirce.

\section{Os interpretantes nas formas de crença}

Como é bem sabido pelos estudiosos, Peirce elege quatro métodos de fixação de crenças, a saber, tenacidade, autoridade, a priori e científico, listados na mesma sequência de exposição em que aparecem no artigo

\footnotetext{
${ }^{7}$ Por outro lado, kairos é aqui tomado como o tempo subjetivo, tal como pode ser sentido psicologicamente.
} 
original. Comecemos refletindo sobre crença científica, seguindo-se o método da autoridade, a priori e, por fim, o da tenacidade. Modifico a sequência original com a hipótese de fechamento gradual do diálogo semiótico de cada uma delas com o objeto dinâmico. Esse tipo de crença surge pelo diálogo semiótico contínuo das teorias com a experiência, e as teorias adotadas como verdadeiras são aquelas que têm boa aderência ${ }^{8}$ com os fatos. É essa boa aderência entre signos e seus objetos que proporcionam ancorar interpretantes lógicos comuns a toda a comunidade de investigadores. É importante notar que as ciências da natureza, onde essa comunidade é mais ampla que nas ditas ciências humanas ${ }^{9}$, produz interpretantes que independem de idiossincrasias culturais ou ideológicas - pode-se estudar Física, por exemplo, em países ideologicamente díspares, fato que era mais ainda evidente durante a guerra fria dos anos sessenta, e ter-se-ão acolhidas as mesmas teorias como verossímeis. Até onde se sabe, não há registros de ciências da natureza ideologicamente de esquerda ou de direita. A razão para essa universalidade é o cabal reconhecimento da distinção entre objetos imediato e dinâmico que se efetiva na própria prática científica. As teorias dotadas do primeiro buscam incessantemente o segundo. O lado externo dos objetos sob investigação são expressão genuína de seu lado interno, ao menos no que respeita ao que sustenta sua estrutura lógica, pois é ela que baliza a estrutura lógica dos interpretantes. Não há, deve-se dizer, um lado oculto da realidade que não se mostra de modo algum. Esse seria o caso da coisa em si de Kant, que, para Peirce, carece de significação possível: o que nunca adentra um teatro de reações não pode ser considerado real. Ser real e ser cognoscível são, na filosofia de Peirce, expressões equivalentes ${ }^{10}$. Essa condição não precisa de outra legitimação senão o da interação das categorias peircianas. Primeiridade e Terceiridade devem aparecer pelo seu lado exterior, a saber, como

\footnotetext{
${ }^{8}$ Trabalhei o conceito de "aderência" em um sentido bem conhecido em Física em (IBRI, 2012) e (IBRI, 2015). Essa abordagem do termo é diferente da forma como Peirce o usa, a saber, adotar ou afiliar-se a alguma opinião geral (ver CP 2.427, 4.63, 5.382, 6.492).

${ }^{9}$ Muitas razões podem ser atribuídas a essa diferente universalidade das ciências nas duas áreas. Elencam-se, por exemplo, problemas de método investigativo e de desuniformidade de terminologia (vide "Ética da Terminologia" de Peirce, CP 2.219-226 / EP 2.263-266), a par da experiência histórica que diferencia as reconhecidamente jovens humanidades das já bem mais maduras ciências ditas naturais.

${ }^{10}$ Ver, por exemplo, CP 5.310: “[...] o que quer que seja significado por um termo tal como 'o real' é cognoscível em algum grau e, assim, é da natureza de uma cognição, no sentido objetivo do termo. ”
} 
Segundidade, a categoria onde as indeterminações dos contínuos sem forma (primeiridade) e com forma (terceiridade) se determinam como fatos particulares hic et nunc, mostrando-se a qualquer mente aberta à sua interpretação. As crenças científicas não podem, assim, cristalizar seus hábitos, constituídos pelas teorias que balizam a leitura dos fenômenos. Esses, os fenômenos, são manifestações de objetos dinâmicos que desafiam a sua representação, como objetos imediatos, a ser genuína ou, em outras palavras, a estar sob a tensão permanente da necessária aderência entre curso dos fatos e predições teóricas. Poder-se-ia dizer que as crenças científicas são crenças vivas, na medida mesma em que sobrevivem sustentadas no diálogo interpretável entre os signos e seus objetos. Para tais crenças, a alteridade tem sempre a última palavra, pois é ela que impõe qual a forma lógica que devem ter as mediações, de modo que essas balizem com eficiência a conduta a ser adotada no teatro de reações.

É interessante realçar que ao denominar as crenças científicas de crenças vivas, permite-se estender uma característica típica da prática das ciências a todos os seres que, de um modo ou de outro, mantém diálogo vivo com os fenômenos em que eles estão inseridos. Animais e plantas não podem cristalizar suas condutas, sob pena de perecerem. Seu objeto dinâmico, a vida, baliza as mediações que permitem agir na direção da sobrevivência, adotadas pelas espécies na forma de interpretantes lógicos dos signos produzidos pelo meio ambiente. Tenacidade, nesse caso, pode significar morte, como exporei adiante.

Assim, pode-se dizer que seres vivos que sobreviveram ao longo da evolução desenvolveram mediações bem-sucedidas para balizarem suas condutas. Estudar os hábitos de uma espécie é representar os interpretantes que ela adotou para coabitar com os demais seres que constituem seu meio ambiente. O processo evolucionário como um todo pode ser entendido como uma complexa rede lógica desenvolvida por generalização de procedimentos eficazes para fins vitais. Trata-se de um processo semiótico de aprendizagem pragmática, isto é, de movimento reflexivo que incorpora, no universo simbólico das espécies, generalizações de condutas conducentes ao crescimento, à diversificação e à manutenção da vida. Aprender é o verbo que é partilhado pelas crenças científicas e pelas espécies naturais. Em ambos os casos se tem que lidar com a segundidade dos fatos, interpretando-os e incorporando-os 
pragmaticamente ao modo de agir. Em ambos os casos, a última palavra é dada pelos fatos - o objeto dinâmico se impõe ao objeto imediato contido nos interpretantes lógicos.

Vejamos agora o segundo tipo de crença, na sequência que adotamos, diferente, conforme já mencionado, do que consta no ensaio de Peirce. Trata-se da crença por autoridade. Como Peirce ressalta, ela é bastante eficiente no sentido de promover ações de uma coletividade voltada para fins eleitos pela autoridade. Exemplos expressivos desse tipo de fixação de crença são as instituições em que vigem uma hierarquia rígida, como nas organizações militares. Nessas há diálogo semiótico com a experiência para balizar a conduta cuja interpretação final dos fatos fica a cargo da autoridade. O sucesso ou fracasso das ações implicam, geralmente, em mérito ou demérito dos que comandam. Os executores da ação seguem um plano de ação que lhes é imposto pela autoridade conjecturar abdutivamente, colocar estratégias em prática e interpretar seus resultados são prerrogativas de quem comanda. Aos executores cabe, apenas, a generalização empírica das ações em sua segundidade. De certa forma, as teorias estratégicas balizam-se pelos resultados práticos, e o diálogo com a experiência, em caso de guerras, por exemplo, são agudizados pelo jogo cruelmente possível entre vitória e derrota, entre vida e morte. A necessidade de eficiência é, nesses casos, vital, e nenhum interpretante emocional tem lugar em face da necessidade de se prever o fato futuro mediante a melhor análise lógica possível ${ }^{11}$.

O esquema centralizado das interpretações da crença por autoridade verificável em instituições militares atenua-se, parece lícito afirmar, nos casos das corporações empresariais, onde há hierarquias de comando que, não necessariamente, se caracterizam por autoridade, mas sim por esquemas de liderança. Nesses últimos casos, pode-se supor que em diversos níveis da hierarquia há produção de interpretantes lógicos baseados na experiência fática e que eles circulam em rede comunicativa que promove um comércio de signos e significações. Os personagens de

\footnotetext{
${ }^{11}$ Peirce realça a efetividade do método da autoridade, realçando seu papel social em estados autoritários: "O método da autoridade governará sempre a massa da humanidade; e aqueles que dominam as várias formas de força organizada dentro do Estado nunca serão convencidos que o pensamento perigoso não deve, de alguma forma, ser suprimido. Se a liberdade de expressão for desembaraçada das formas mais grosseiras de constrangimento, então a uniformidade de opinião será assegurada por um terrorismo moral, ao qual a respeitabilidade da sociedade dará a sua inteira aprovação. Seguir o método da autoridade é o caminho da paz.” (CP 5.386)
} 
uma corporação, dependendo dos graus de liberdade que lhes são facultados, participam da elaboração dos planos de ação e da interpretação dos resultados, sugerindo hipóteses e planos alternativos. De qualquer modo, mesmo nesses casos, decisões finais podem ser tomadas unilateralmente pela autoridade. Nesses dois exemplos, predominam, suponho, os interpretantes lógicos em face da necessidade premente de sucesso das ações perpetradas. É interessante notar, contudo, que interpretantes emocionais nos casos descritos podem estar associados aos fins da ação, na medida mesma em que elas podem estar sujeitas a juízos de natureza moral. As guerras, parece óbvio dizer, nem sempre têm finalidade libertária. Abundam na história humana as que incidem em dominação final pela força, e seus resultados, é evidente, ficam sujeitos a juízos de valor que envolvem interpretantes emocionais.

De sua vez, empresas buscam vender seus produtos em um mercado de consumidores que, muitas vezes, são seduzidos por interpretantes emocionais cuidadosamente pensados por estratégias de marketing. Porém, essa dimensão ética, complexa como deve ser, não pode ser satisfatoriamente analisada na instância desse texto, cabendo, não obstante, mencioná-la pela sua importância e pela sugestão de aprofundamento da reflexão que ela enseja.

Tomemos agora a crença a priori para análise. Tais crenças se fixam não por um diálogo com objetos dinâmicos, pois esses estão vedados à experiência - não são fenomenológicos, como diria Kant. Peirce afirma ${ }^{12}$ ser esse tipo de crença fixado pela tendência humana em crer naquilo que pode lhe ser conveniente, cumprindo um certo papel de trazer conforto espiritual a quem crê. Contudo, esse método está longe de conseguir um acordo universal de opiniões, fixando-se por meio de doutrinas que afirmam a realidade de objetos cujo lado externo não pode ser experienciado, permanecendo apenas interiores ao que dele em teoria se declara. Entre esses casos, encontram-se todas as metafísicas que afirmam a priori a realidade de objetos que cumprem papel de dar sentido à finitude humana, pelas promessas de atemporalidade em uma vida transcendente a essa onde, também, os ímpios seriam finalmente justiçados. A obra de Kant não foi apenas profusa em alertar a falta de cientificidade dessas

\footnotetext{
${ }^{12} \mathrm{Em} \mathrm{CP}$ 5.386, se lê: "O método à priori distingue-se por suas conclusões confortáveis. É da natureza desse processo adotar qualquer crença para a qual estejamos inclinados, e há certas lisonjas para a vaidade humana nas quais todos acreditamos por natureza até sermos acordados de nosso agradável sonho por alguns fatos rudes. ”
} 
metafísicas, mas, também, de tacitamente mostrar os riscos de exercício de poder da autoridade que poderia fazer nascer do signo seus objetos ${ }^{13}$, tal qual faz o imaginário de um escritor em literatura. Sem a âncora da realidade, espreita os homens, pode-se dizer, o possível jugo exercido por quem arbitra o que seja o verdadeiro. A crença em objetos excluídos da experiência possível ${ }^{14}$ faz com que sua aceitação como realidade se faça tão-somente por interpretantes emocionais, uma vez que os interpretantes lógicos pragmáticos são factíveis quando balizados por objetos dinâmicos, a saber, objetos reais. Pode-se dizer, que do método científico até o a priori, passando pelo da autoridade, gradativamente se sobrelevam os interpretantes emocionais sobre os lógicos, uma vez que aqueles passam a ancorar as crenças. Isso, a meu ver, se dá por uma espécie de gradual crepúsculo, permitindo-me essa metáfora, da realidade enquanto algo que radicalmente independe de nossas opiniões sobre ela. Esse movimento, é aqui importante notar, esgarça o universal acordo de opiniões promovido pelo balizamento do signo pelo objeto, levando-o a relativismos advindos do arbítrio dos objetos apenas criados no interior do signo. Arbítrio, permite-se dizer, é o que circula nas veias de quem simplesmente exerce poder. O que deveria ser hipótese em um argumento são, torna-se, sem credenciais, teoria verdadeira. O que deveria ser mediação cognitivamente construída torna-se normativo da conduta da alteridade.

Seria o último método de fixação das crenças, a Tenacidade, o representante mais intenso do gradual crepúsculo da realidade trazido pelos dois métodos anteriores? Tudo leva a crer que sim, mediante o conceito que Peirce atribui a esse método: tenaz é todo método que fixa crenças por manter imutáveis as opiniões constituídas sobre os objetos, não importando o que possam trazer novos fenômenos, uma vez que a mente tenaz os ignora em prol de um valor mais alto, a saber, a estabilidade de uma concepção de mundo que não se deixa ameaçar pela experiência. Em verdade, esse método, busca vedar totalmente a mente aos objetos dinâmicos que poderiam afetar os objetos imediatos que estão no interior das opiniões. Trata-se, à luz do vínhamos conceituando, de uma crença morta, não obstante possivelmente atue, para quem a detém, como viva. Há aqui, suponho, a predominância intensa de interpretantes

\footnotetext{
${ }^{13}$ Ver a Metafísica dos Costumes de Kant: “o abuso mais intolerável da suprema autoridade” (MM 320).

14 Essa é, como bem se sabe, uma expressão kantiana universal.
} 
emocionais sustentados pelas certezas imutáveis dos enunciados que constituem suas opiniões sobre o mundo. Penso que uma pessoa ou conjunto de pessoas que assim creem, sobrevivem em um mundo que lhes é próprio, privativo, mas que ao interagir com mente ou mentes que praticam crenças vivas conflitam de modo inevitável com elas. Fenomenologicamente, sua segurança emocional baseia-se em evitar os riscos de rever suas crenças por dar voz ao objeto dinâmico em suas manifestações na experiência. A mente tenaz, assim, jamais conjectura. Ao gerar estabilidade e conforto emocional para si, motivo maior de seu modo de ser, cria em volta de si, no âmbito da rede social onde se encontra, conflitos de relacionamento, podem-se dizer, insuperáveis. Há certas pessoas, penso eu, que, uma vez inseridas em um meio social, atuam como campos físicos de força, tal como o magnético e o elétrico, gerando de si o alto preço que sua tenacidade acaba cobrando dos outros, uma tridimensional e aguda infelicidade. Resta-lhes, alternativamente, isolarem-se da rede semiótica que os desafia a conjecturar, figura lógica impensável para a mente tenaz, e viverem sua ficção como se fosse realidade. A psicanálise tem, no interior dessa descrição, seu espaço garantido, enumerando as possíveis anomalias psíquicas que a tenacidade pode acarretar.

Parece-me que Peirce ao tratar desse método não faz a devida crítica das possíveis consequências que tal método pode trazer, como busco aqui fazer. Ele, permito-me conjecturar, parece de maneira tácita ironizar sobre aquelas consequências. Em CP 5.386 se lê:

Mas mais do que tudo, admiro o método da tenacidade por ser direto, e pela sua força e simplicidade. Os homens que o prosseguem distinguemse pelo seu caráter decidido, que se torna muito fácil com tal regra mental. Eles não perdem tempo a tentar decidir o que querem, mas, apressandose como um relâmpago sobre qualquer alternativa que lhes apareça primeiro, mantém-se fiéis a ela até ao fim, suceda o que suceder, sem um instante de indecisão. Esta é uma das esplêndidas qualidades que geralmente acompanha o sucesso brilhante e temporário. É impossível não invejar o homem que despede a razão, embora saibamos como isso deve terminar no fim.

Não posso deixar de pensar que apenas uma melancólica ironia, que exala um interpretante emocional bastante amargo, realça um sucesso da mente tenaz sem explicitar o que ele seria. Talvez se possa pensar nas 
personalidades autoritárias que submeteriam outras mentes a seu poder. Contudo, pode-se legitimamente deixar aqui uma expressiva questão: por quanto tempo verdade, em sua versão marcadamente realista tal como está presente no próprio coração da filosofia de Peirce, permaneceria calada? Deixemos que seu criador responda:

\begin{abstract}
Iluda-te o quanto quiseres, tens uma experiência direta de algo reagindo contra ti. Podes supor que haja alguma substância onde, ambos, o ego e o não-ego possuem as raízes de seus seres; mas isso é irrelevante. O fato da reação existe. Há a proposição de que assim o é, seja qual for tua opinião. A essência da verdade reside em sua resistência em ser ignorada. (CP 2.139 - meu grifo).
\end{abstract}

\title{
Referências
}

IBRI, Ivo A. Choices, dogmatisms and bets: justifying Peirce's realism. In: Veritas, PUCRS, v. 57, n. 2, p.51-61, 2012.

. The ontology of action in Peirce's philosophy. In: The status of thought in honorem professor Ivan Mladenov. Elka Traykova, Paul Cobley, Miryana Yanakieva, Raya Kuncheva, Andrey Tashev (Eds.). [s.l], Sofia Publishind Center, 2015.

KANT, Immanuel. The Metaphysics of Morals. Cambridge University Press; Edited by Mary J. Gregor, 2nd edition, 1996.

PEIRCE, Charles S. The essential Peirce: selected philosophical writings. Edited by Nathan Houser and Christian Kloesel. Bloomington: Indiana University Press, c1992. V. 1 [Citado EP, seguido do número do volume e do número da página].

. The essential Peirce: selected philosophical writings. The Peirce Edition Project (Ed.). Bloomington: Indiana University Press, 1998. V. 2 [Citado EP, seguido do número do volume e do número da página].

. Writings of Charles Sanders Peirce: a chronological edition. The Peirce Edition Project (Ed.). Bloomington: Indiana University Press, 1982-2010. 8 V. [Citado W, seguido do número do volume e do número da página].

. Collected Papers of Charles Sanders Peirce. Edited by Charles Hartshorne, Paul Weiss, and Arthur W. Burks. Cambridge, Massachusetts, Harvard University Press, 1931-35 e 1958, 8vols. [Citado CP, seguido do número do volume e do número do parágrafo]. 